\title{
HISTOLOGICAL STRUCTURE OF THE HUMAN BIOLOGICALLY ACTIVE POINT (BAP) ST 36
}

\author{
N. Dimitrov ${ }^{1}$, D. Sivrev ${ }^{1}$, D. Atanasova ${ }^{2}$ \\ ${ }^{1}$ Department of Anatomy, Faculty of Medicine, Trakia University, Stara Zagora, Bulgaria \\ ${ }^{2}$ Institute of Neurobiology, Bulgarian Academy of Sciences, Sofia, Bulgaria
}

\begin{abstract}
Biologically active point (BAP) $\mathrm{ST}_{36}$ is one of the most important and most commonly used points in the traditional Chinese medicine (TCM). A correlation between the location of acupuncture points and channels in humans and animals has been established. In the human $\mathrm{ST}_{36}$ is located on the stomach meridian - 3 cun (1 handbreadth) down and 1 fingerbreadth lateral to the anterior crest of the tibia, on the tibialis anterior muscle. The target of this study is to describe the histological structure of biologically active point (BAP) $\mathrm{ST}_{36}$ in the human by using the classic histological techniques. We observed normal histology structures in $\mathrm{ST}_{36}$ point in the human.
\end{abstract}

Key words: acupuncture, BAP - biologically active point, histology, human, $\mathrm{ST}_{36}$, traditional Chinese medicine (TCM).

\section{INTRODUCTION}

Biologically active point (BAP) $\mathrm{ST}_{36}$ is one of the most important and most commonly used points in the traditional Chinese medicine (TCM) (1). A correlation between the location of acupuncture points and channels in humans and animals has been established (2). In the human $\mathrm{ST}_{36}$ is located on the stomach meridian - 3 cun ( 1 handbreadth) down and 1 fingerbreadth lateral to the anterior crest of the tibia, on the tibialis anterior muscle (3).

\section{Aim and objectives}

The aim of this study is to describe the histological structure of biologically active point (BAP) $\mathrm{ST}_{36}$ at the human by utilizing the classic histological techniques.

\section{METHODS}

We took material from the $\mathrm{ST}_{36}$ point of human cadavers. The $\mathrm{ST}_{36}$ point was localized by determining relations between standard anatomical structures and with the help of KWD-808 device for measuring the skin conductivity (4). The material was embedded into paraffin and cut in $5 \mu \mathrm{m}$ thick sections. Four standard stains were applied: Mallory, H\&E, toluidine blue and Bismarck brown.

\section{RESULTS}

In the $\mathrm{ST}_{36}$ point in the human normal histology structures were observed: skin, subcutaneous adipose tissue, blood vessels, nerves, sebaceous and sweat glands, and mast cells. (Figures 1A, B; 2A-F). In some areas of the skin indentations and differences in the thickness of the epidermis and the loose connective tissue layers were found, but these differences were not pronounced. In the subcutis of the $\mathrm{ST}_{36}$ point in the human a large number of lypocytes were demonstrated. The superficial fascia was found to blend with the reticular layer of the dermis. Elastic fibers were found around the glands, the hair follicles, and superficial fascia. In human skin mast cells were visualized around the blood vessels, the sweat glands, the sebaceous glands, and the hair follicles. (Figures 2C, E, F).

\section{DISCUSSION}

This normal histology structures are confirmed by other authors. $(5,6,7,8,9,10)$. No significant differences between the skin structure of acupuncture point $\mathrm{ST}_{36}$ and normal skin outside the said point could be defined, despite such differences were reported by other authors $(11,12)$.

\section{CONCLUSIONS}

In the human $\mathrm{ST}_{36}$ point we observed normal histology structures. Accumulation of mast cells, primarily in the vicinity of blood vessels and around the glands and the hair follicles, was observed. 

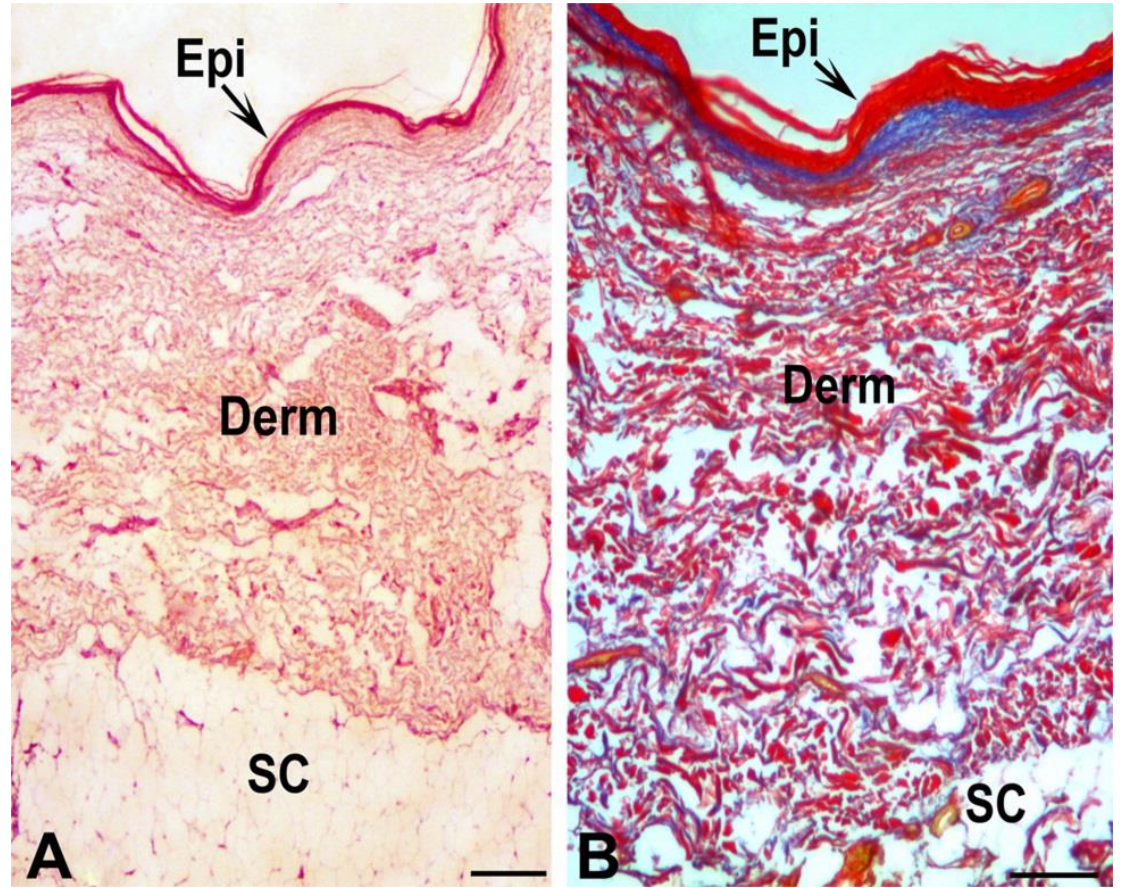

Figure 1. (A) Routine H\&E and Mallory (B) staining to visualize normal histological structures in ST36 point in the human. Epidermis (Epi), dermis (Derm) and subcutaneous adipose tissue (SC). Scale bars: $50 \mu \mathrm{m}$.

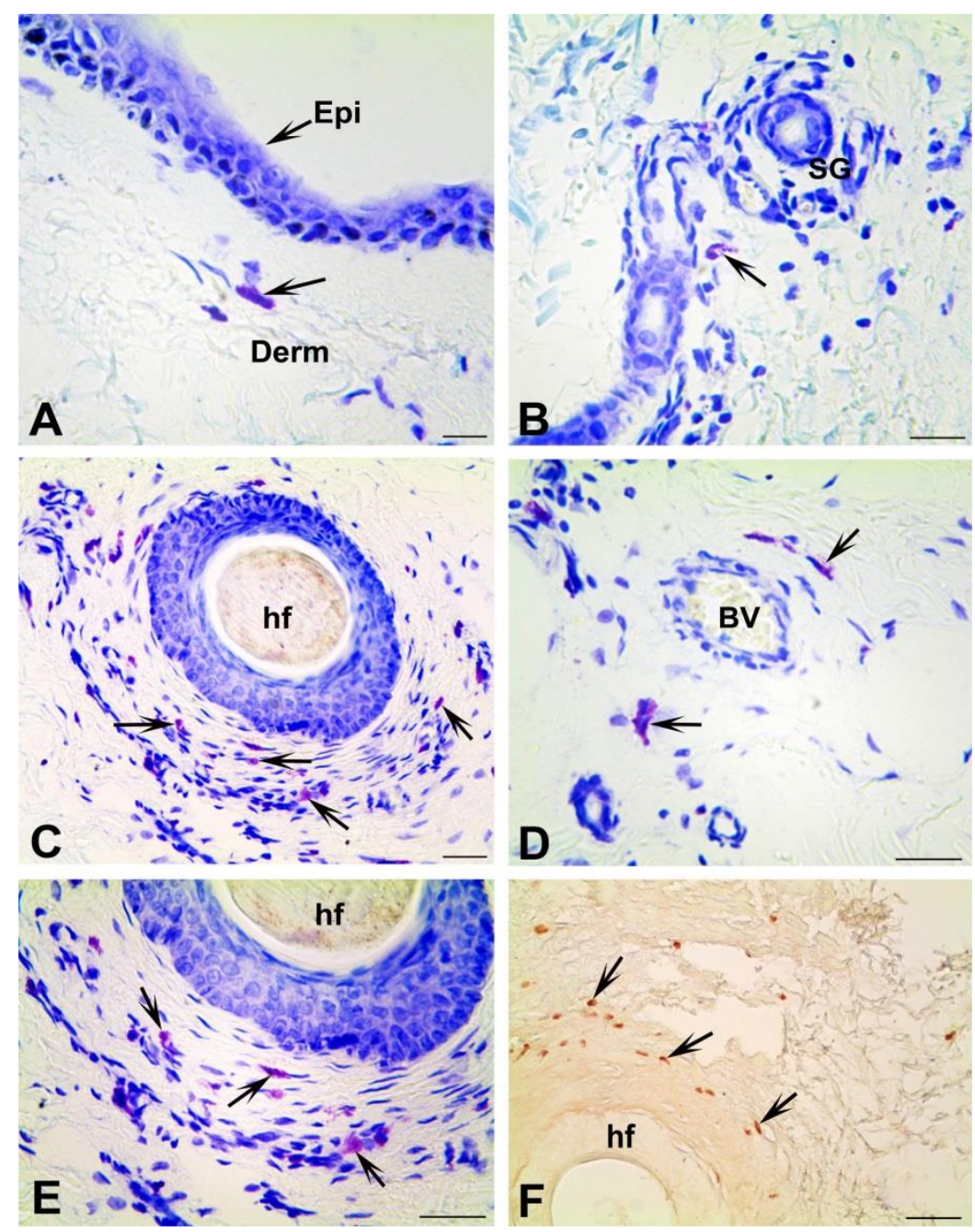

Figure 2. (A-E) Toluidine blue staining and specific Bismark brown staining (F) to illustrate the mast cells (arrows) in the field of ST BAP. Note accumulation of mast cells on the epidermis - dermis border (A) and 
around the hair follicles (C, E, F). Epidermis (Epi), dermis (Derm), hair follicles (hf), sweat gland (SG), blood vessels (BV). Scale bars: $50 \mu \mathrm{m}$.

\section{REFERENCES}

1. Dimitrov, N., Pirovski N., Sivrev D. Application of aiurveda and traditional chinese medicine in the present medical practice. Scientific conference with international participation, scientific researchers volume III, part I, 346- 350, 2008.

2. Dimitrov, N., Sivrev D., Staykova Y., Goranova Z. Comparative analysis of biological active channeles in humans and animals. Scientific conference with international participation, scientific researchers volume III, part I, 351-357, 2008.

3. Focks. C. Atlas of acupuncture. p. 168. Elsevier Limited.2008

4. Dimitrov. N., Sivrev D., Pirovski N., Georgieva A., Methods for localization of BAP of the human body. 19-21.Jurnal of Biomedical \&clinical Research, MU Pleven, 2009

5. Metcalfe D., Baram D., and Mekori Y. Mast Cells. Laboratory of Allergic Diseases, National Institute of Allergy and Infectious Diseases, National Institutes of Health, Bethesda, Maryland; and Department of Medicine, Sackler School of
Medicine, Tel Aviv University, Tel Aviv, Israel Physiological reviews Jol. 77, No. 4, 1997.

6. Dung, H.C. Anatomical features contributing to the formation of acupuncture points. Am J Acup. 12, 139143,1984

7. Dornette W. H. L, J.D. The Anatomy of acupuncture p 897. Vol.51,No.8,September, 1975

8. Bossy, J. Morphological data concerning the acupuncture-points and channel network. Elektrother. Res9,1984.

9. Heine H. Zur Morphologie der Akupunkturpunkte. Dtsch Z Akupunktur; 30:75-9., 1987.

10.Heine H. Anatomische Struktur der Akupunkturpunkte. Dtsch Z Akupunktur; 31:26-30. 1987

11.Zhong Am, Wu JL, Hu YL: Study on correlation between the mast cell and acupoint. Shijie Zhenjiu Zazhi, 4:53-58, 1994.

12.Zhang D, Ding G, Shen X, Yao W, Zhang Z, Zhang Y, Lin J, Gu Q. Role of mast cells in acupuncture effect: a pilot study. Explore (NY); 4(3):170-7. do10.1016/j.explore.2008 